\title{
FISCAL COMPETITION, CONVERGENCE AND AGGLOMERATION
}

\author{
ROBERT FENGE \\ MAXIMILIAN VON EHRLICH \\ MATTHIAS WREDE
}

CESIFO WORKING PAPER NO. 2084

CATEGORY 1: PUBLIC FinANCE

August 2007

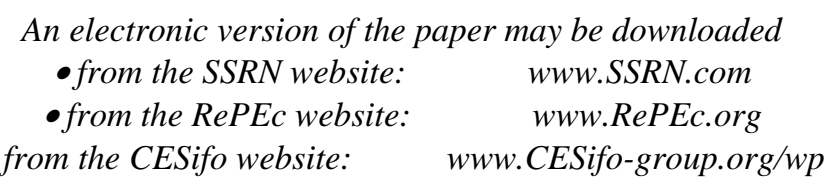




\title{
FisCAL COMPETITION, CONVERGENCE AND AGGLOMERATION
}

\begin{abstract}
This paper analyzes the impact of fiscal competition through infrastructure in a New Economic Geography framework. It is shown that regional competition leads to convergence if the trade costs are high but induces divergence if trade cost have fallen below a certain value. Moreover, fiscal competition yields an overprovision if the trade costs are sizable while it leads to underprovision if the regions are highly integrated. Finally, a trade-off between regional convergence and efficiency arises since the efficient distribution of regional infrastructure requires full agglomeration for sufficiently low trade costs.
\end{abstract}

JEL Code: F12, F15, H87, R12.

Keywords: fiscal competition, infrastructure, agglomeration.

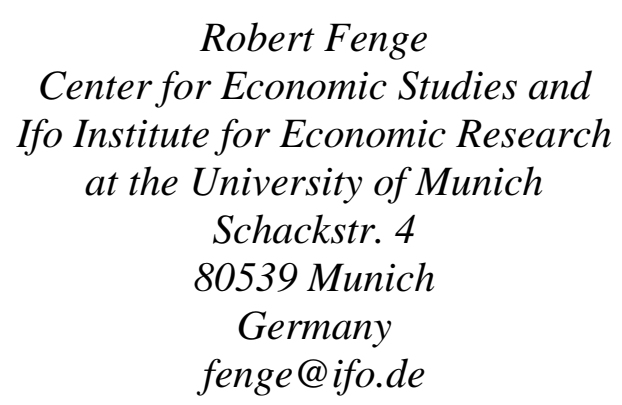

Robert Fenge

Center for Economic Studies and

Matthias Wrede

RWTH Aachen University

Department of Business and Economics

Templergraben 64

52056 Aachen

Germany

mwr@fiwi.rwth-aachen.de

This version: August 2007 


\section{Introduction}

In many federations closer integration is feared to bring about a process of regional divergence. Therefore, regional policies are often designed to countervail the industries' potential tendency for spatial concentration. The European Union, for example, dedicates about $35 \%$ of its budget to structural policies, which are intended to reallocate industry from core to less prosperous peripheral regions (European Commission 2001). At the same time regional competition through taxes or publicly provided goods, that might act as a means to attract mobile capital is suspiciously treated. Following this notion in 1998 an expert group on behalf of the ECOFIN Council listed more than 60 "harmful" tax measures. In a voluntary code of conduct the member states are supposed to refrain from those policies ${ }^{1}$. In this paper we bring together those two issues policy makers are concerned with. From a positive point of view, we analyze under which conditions fiscal competition between regions affects the process of agglomeration - will it hinder or enforce it ? From a normative point of view, we determine whether fiscal competition leads to an efficient outcome in terms of the provision of public inputs as well as the resulting regional allocation of industry. The latter issue addresses the question whether a federal policy reallocating public input resources across regions is necessary in order to achieve an optimal outcome.

Following Martin and Rogers (1995) and Dupont and Martin (2006) who deal with regional policy in the New Economic Geography we model fiscal competition in a framework where regional agglomeration processes are driven by increasing returns on the level of the firms in combination with trade costs and monopolistic competition. We use a footloose capital model (see e.g. Martin and Rogers, 1995; Baldwin et al., 2003) in which regional divergence relies on some asymmetry from the outset. In our analysis two kinds of asymmetries are considered. First, differences in regional infrastructural endowments are taken into account. Due to increasing returns, trade costs and mark-ups on marginal

\footnotetext{
${ }^{1}$ Conclusions of the ECOFIN Council Meeting on 1. December 1997 concerning taxation policy, 98/C $2 / 01$.
} 
costs capital returns are higher in the region with larger stocks of infrastructure. It will be shown that contingent on the level of trade costs differences in regional infrastructural endowments may enforce, other things being equal, agglomeration. The region with the better infrastructure attracts all the industry and becomes the core for sufficiently low trade costs. Second, as an extension differences in regional expenditure shares, i.e. differences in regions' sizes which are the basis of the home-market effect, are also considered. Having a larger home-market constitutes an comparative advantage in those models. We are particularly concerned with the interaction of these two asymmetries.

A series of papers has dealt with tax competition in the New Economic Geography as for example Ludema and Wooton, 2000; Kind et al., 2000; Andersson and Forslid, 2003; Baldwin and Krugman, 2004; Borck and Pflüger, 2006 or Baldwin et. al., 2003. Andersson and Forslid (2003) have already considered public consumption goods, but, to our knowledge, this is the first paper which deals with fiscal competition via public input in such a framework. The public input increases the productivity of the immobile factor labor and is financed by a residence based tax on income. In contrast to Martin and Rogers (1995) we assume that public inputs reduce variable private costs instead of fixed private costs. There is clearly anecdotical evidence that public infrastructure affects not only set up costs, but also variable costs. E.g., improvement in public transportation systems reduce transport time and thus costs per unit.

We derive the following main results: First of all we show that if trade costs are high competition leads to a convergence in the provision of public infrastructure. This reduces agglomeration tendencies which can be traced back to differences in infrastructural endowments but it does not affect the agglomeration process due to size asymmetries. Only if integration gets closer and trade costs are sufficiently low one region may decide not to provide any infrastructure and to free-ride on the other region's infrastructure. The reason is that it benefits from importing goods at low trade costs instead of bearing the costs of infrastructure provision itself. In this case, infrastructure competition accelerates agglomeration. 
From a normative perspective the question arises whether fiscal competition leads both to an optimal aggregate infrastructure provision and to an efficient distribution of infrastructure between the regions. In our model, infrastructure provision in one region exerts a negative externality on the other regions because it attracts industry from other regions. In some sense, this is similar to the external effect arising in tax competition models where capital is mobile but regions do not trade. The standard result in those models with complementarity between the public input and private capital is overprovision of the public input if the elasticity of capital with respect to the public input is larger than the elasticity of capital with respect to the tax (Zodrow and Mieszkowski, 1986; Noiset, 1995; Sinn, 1997). Since in our analysis the public input is financed by a tax on a completely inelastic base (residents' income) the same result would appear if this were the only externality. However, the possibility of trade in combination with the public good characteristics of infrastructure adds another externality of infrastructure provision which is positive. For low trade costs it is cheaper for a region to import industrial goods from other regions than to provide its own infrastructure in order to have industry located nearby. This means the region free-rides on the concentration of public infrastructure in the foreign region and saves the costs of providing infrastructure. In other words, the region that provides all the infrastructure does not take into account the cost reduction of imported manufactured goods in the foreign region. If trade costs are sufficiently low this positive externality dominates and an underprovision of infrastructure is the outcome of fiscal competition. On the contrary, if the trade costs are sizable we show that the amount of aggregate infrastructure provided in a decentralized equilibrium is too high compared to a centralized provision of regional infrastructure. The reason is that imports are expensive when trade costs are high and accordingly it is important to have industry located in the respective regions such that the negative externality dominates.

Concerning the distribution of infrastructure across regions, low trade costs allow the regions to import industrial goods at low consumer prices. In such an integrated market a central government chooses to concentrate public infrastructure in one region which attracts all industry to this core region and maximizes the aggregate productivity of the 
industrial sector while the expenses in trade costs remain moderate. For high trade costs, in contrast, a central government would distribute infrastructure equally across regions because the benefit from saving trade costs is higher than the loss in overall productivity. We show that for a range of higher trade costs a decentralized infrastructure allocation would lead to a symmetric provision whereas a central government would place all infrastructure in one region and implement an agglomeration pattern. The reason is that a single region benefits from increasing aggregate productivity only to the extent of the imported goods weighted at trade costs while the central government faces the full productivity gain. Therefore, regions start to prefer the concentration of infrastructure and the agglomeration of industry only at a lower rate of trade costs than the central governments does. Note that these results arise although we abstract from local spillover-effects between firms in our model. Such spillover effects can also lead to lower degree of agglomeration than desired from a welfare perspective and Martin and Ottaviano (1999) have shown that in this case a trade-off between convergence and efficiency arises. Agglomerated regions will attain higher growth rates in their model. Martin (1999) pursues this argument to the question whether inter- or intra-regional infrastructure should be provided. In our model, however, it is shown that such a trade-off may arise due to the mere possibility of trade at low cost in combination with the public good characteristics of infrastructure.

The next section introduces into the basic model and derives the impact of regional infrastructure on the long-run allocation of industry. Section 3 describes the externality of infrastructure provision which arises if fiscal competition between regions takes place and determines the Nash equilibria for critical values of trade freeness. Section 4 contrasts the Nash equilibria with the allocation of a federal government taking account of the externalities. Section 5 extends the model to asymmetry in population size and to congestion costs and discusses the qualifications of the results. Section 6 summarizes the main findings and relates to policy issues. 


\section{The Model}

Following Martin and Rogers (1995) we use a model where the fixed cost in the manufacturing sector consists of a internationally mobile factor which Baldwin et al. (2003) label the footloose capital model. A federation consists of two regions $H$ and $F$ which are symmetric in terms of preferences, technology and trade costs. There are two sectors, a manufacturing sector $(M)$ characterized by increasing returns, monopolistic competition and iceberg trade costs, and a perfectly competitive sector labelled agriculture $(A)$ which produces under constant returns a homogenous good that is traded without costs. This good is produced in both regions and is taken as the numeréraire, i.e. its price $p_{A}$ is normalized to one. Individuals consume an agricultural good $C_{A}$ and a composite manufactured good $C_{M}$ as in Dixit and Stiglitz (1977). The utility of consuming the agricultural and the composite manufactured good is a logarithmic quasi-linear function where $\mu$ is the expenditure share of the composite manufactured good. ${ }^{2}$ The composite manufactured good again is given by a continuum of $n$ differentiated varieties. In general individuals prefer to consume as many different varieties as possible. Their willingness to substitute between the quantities $m_{i}$ of the varieties is given by the substitution elasticity $\sigma>1$. Hence, utility is: ${ }^{3}$

$$
U=C_{A}+\mu \ln C_{M}+\mu-\mu \ln (\mu) ; \text { where } C_{M}=\left[\int_{0}^{n} m_{i} \frac{\sigma-1}{\sigma} d i\right]^{\frac{\sigma}{\sigma-1}}
$$

Denoting personal net income by $y$, the budget constraint is

$$
y=C_{A}+P C_{M},
$$

\footnotetext{
${ }^{2}$ Since expenditure shares are exogenous in the model, income effects do not arise. Using a quasi-linear utility function which captures only substitution effects exhibits all relevant features of the model and simplifies calculations. See Pflüger (2004) for a detailed analysis of the standard model with quasi-linear utility.

${ }^{3} \mu-\mu \ln (\mu)$ is added to simplify the expression for indirect utility; see below.
} 
where the economy's consumer price index of the composite good $P$ can be expressed in terms of the prices $p(i)$ of varieties $i$ :

$$
P=\left[\int_{0}^{n} p_{i}{ }^{1-\sigma} d i\right]^{\frac{1}{1-\sigma}} .
$$

Utility maximization leads to the aggregate demands for agricultural and manufactured goods: $C_{A}=Y-\mu$ and $C_{M}=\mu / P$, respectively, and the indirect utility $V$ :

$$
V=y-\mu \ln (P) .
$$

Demand for each single manufactured variety $m_{i}$ can be calculated by minimizing the costs of consuming a given amount of the composite good $C_{M}$. This yields

$$
m_{i}\left(p_{i}\right)=\mu \frac{p_{i}^{-\sigma}}{P^{1-\sigma}} .
$$

On the supply side, there are three productive factors: interregionally immobile labor, mobile capital and local infrastructure. The number of immobile workers in region $j=$ $H, F$ is denoted by $L_{j}$, the number of capital owners by $K_{j}$, where each capital owner owns one unit of capital. The total stock of capital is given by $K^{W}=K_{H}+K_{F}$, while world labor endowment is given by $L^{W}=L_{H}+L_{F}$. Capital is invested internationally but its return is repatriated. The agricultural good is produced with labor under a linear technology. Perfect competition leads to marginal cost pricing. Furthermore the wage is equal to the marginal product of labor, i.e. one. Manufacturing firms produce with a non-homothetic technology and each firm produces one variety. A firm located in region $j$ requires one unit of capital and, per unit of output, $c_{j}$ units of labor. Total costs of a firm which produces variety $i$ are $R_{j}+c_{j} M_{i}$, where $R_{j}$ is the reward to capital in region $j$ and $M_{i}$ is the output of this firm.

In the Dixit-Stiglitz model of monopolistic competition mill pricing is optimal. Hence, indicating producer prices by a hat, in the region where the variety is produced $p_{i}=\hat{p}_{i}$ holds, and in the foreign region $p_{i}=\tau \hat{p}_{i}$ is fulfilled, where $\tau$ are iceberg trade costs with $\tau>1$. Profits of firm $i$ in region $j$ are

$$
\Pi_{i}^{j}=\left(\hat{p}_{i}-c_{j}\right) M_{i}-R_{j}
$$


Market clearing for a variety $i$ produced in region $j$ implies $M_{i}=m_{i}\left(\hat{p}_{i}\right)\left(K_{j}+L_{j}\right)+$ $\tau m_{i}\left(\tau \hat{p}_{i}\right)\left(K_{k}+L_{k}\right), k \neq j, j, k \in\{H, F\}$. Hence, profit maximization leads to

$$
\hat{p}_{i}=\frac{c_{j} \sigma}{\sigma-1} .
$$

Since all firms in a single region set the same price for each variety, local consumers demand the same quantity of all local varieties and we may therefore refer to regions instead of varieties. The regional price index of manufactured goods in region $j$ follows from (3), which is given by the sum of local produced $\left(n_{j}\right)$ and imported varieties $\left(n_{k}\right)$.

$$
P_{j}=\left[\hat{p}_{j}^{1-\sigma} n_{j}+\left(\hat{p}_{k} \tau\right)^{1-\sigma} n_{k}\right]^{\frac{1}{1-\sigma}}, \quad k \neq j, \quad j, k \in\{H, F\}
$$

Variable $\operatorname{costs} c_{j}$ depend on local infrastructure in the respective region. The better the local public good supply is, the lower variable costs are. In contrast to Martin and Rogers (1995), we assume that investment in local infrastructure $\left(X_{j}\right)$ reduces the variable factor's input coefficient $\left(c_{j}\right)$ in the production of the manufacturing sector. Each region invests an amount $X_{j}$ in infrastructure in order to improve the quality of local infrastructure.

$$
X_{j}=c_{j}^{1-\sigma}
$$

The implicit assumption behind this definition is that the productivity of the variable input factor increases with local infrastructure. Moreover it may increase at a diminishing, constant or increasing rate depending on $\sigma$ (diminishing rate if $\sigma>2$ ), since the production function of the monopolistic competitive sector is given by:

$$
Q_{j}=X_{j}^{\frac{1}{\sigma-1}} L_{j}
$$

where $Q_{j}$ is total output of this sector in region $j$. Hence the output elasticity of infrastructure is set to $\frac{1}{\sigma-1}$, which simplifies our analysis. ${ }^{4}$

To finance infrastructure income will be taxed in each region according to the residence principle. Note that this implies that taxation has no direct impact on demand for

\footnotetext{
${ }^{4}$ Expressing the input coefficient in terms of the elasticity of substitution $\sigma$ is a common way to simplify new economic geography models (Fujita et. al., 1999, p. 54; Baldwin et. al., 2003, p. 23).
} 
manufactured goods, since we have assumed that there are no income effects in the markets for manufactured goods. Eventhough the residence principle seem unrealistic with respect to capital taxation we use it in order to focus on competition via the public input solely.

For now we model infrastructure as a pure public good, that is non-rivalry in its usage. Later on we also consider congestion costs in the provision of infrastructure and show how the results change if we have an impure public good.

Using the prices from (7), the definition of the price index (8), and the market clearing condition, the profits of each firm in region $j$ from (6) are

$$
\Pi_{j}=X_{j} \frac{\mu}{\sigma}\left(\frac{\left(K_{j}+L_{j}\right)}{X_{j} n^{j}+\tau^{1-\sigma} X_{k} n^{k}}+\tau^{1-\sigma} \frac{\left(K_{k}+L_{k}\right)}{X_{k} n^{k}+\tau^{1-\sigma} X_{j} n^{j}}\right)-R^{j} .
$$

\subsection{Short-Run Returns}

In the monopolistic competition framework, free and instantaneous entry of firms drives pure profits to zero and the reward to capital is equal to the operating profit. Furthermore, each firm requires one unit of entrepreneurial capital (i.e. $n=K^{W}$ ), such that the number of local varieties is equal to the stock of employed capital. The share of industry or capital employed in region $H$ can be defined as $s_{n}=n_{H} / n=n_{H} / K^{W}$, where $n=n_{H}+n_{F}$. Note that $K_{j}$ represents the amount of capital, which is owned by region $j$, whereas $n_{j}$ represent the amount of capital that is invested in region $j$. The share of population in region $H$ $\left(s_{\text {pop }}\right)$ is exogenously given by the regional factor endowments $\left(L_{H}, K_{H}\right)$ :

$$
s_{\text {pop }}=\frac{K_{H}+L_{H}}{N}
$$

where $N \equiv K^{W}+L^{W}$ indicates worldwide population.

Using the fact that pure profits are zero, the short-run capital returns of both regions result from (11) as:

$$
\begin{aligned}
R_{H} & =\frac{\mu}{\sigma} X_{H}\left(\frac{s_{p o p}}{\Delta_{H}}+\frac{\phi\left(1-s_{p o p}\right)}{\Delta_{F}}\right) \frac{N}{n} \\
R_{F} & =\frac{\mu}{\sigma} X_{F}\left(\frac{\phi s_{p o p}}{\Delta_{H}}+\frac{\left(1-s_{p o p}\right)}{\Delta_{F}}\right) \frac{N}{n}
\end{aligned}
$$


with $\Delta_{H}=X_{H} s_{n}+X_{F} \phi\left(1-s_{n}\right)$ and $\Delta_{F}=X_{F}\left(1-s_{n}\right)+X_{H} \phi s_{n}$,

where $\phi=\tau^{1-\sigma}$ is the degree of trade freeness with $0<\phi \leq 1$. These short run capital returns illustrate the two opposing effects firms consider, when choosing their location. On the one hand they prefer the larger market (greater $s_{p o p}$ ) and on the other hand they prefer the less crowded one (less competitors for input factors, i.e. smaller $s_{n}$ ). Finally, note that average short run returns are independent of population distribution and infrastructure endowment:

$$
s_{n} R_{H}+\left(1-s_{n}\right) R_{F}=\frac{\mu N}{\sigma n} \equiv \bar{R} .
$$

\subsection{Long-Run Equilibrium}

In the long-run equilibrium, capital owners cannot increase capital returns by relocation:

$$
\begin{aligned}
& s_{n}=0 \text { if } R_{H}-\left.R_{F}\right|_{s_{n}=0}<0 \Leftrightarrow \chi<\frac{\phi}{s_{p o p}+\left(1-s_{p o p}\right) \phi^{2}} \\
& s_{n}=1 \text { if } R_{H}-\left.R_{F}\right|_{s_{n}=1}>0 \Leftrightarrow \chi>\frac{s_{p o p} \phi^{2}+1-s_{p o p}}{\phi} \\
& s_{n}=\frac{s_{p o p}}{(1-\phi \chi)}-\frac{\phi\left(1-s_{p o p}\right)}{(\chi-\phi)} \text { otherwise, }
\end{aligned}
$$

where $\chi=X_{H} / X_{F}$. Either capital is completely located in the region with the larger returns or capital returns are equalized and both regions employ capital. If both regions have the same quality of infrastructure, the larger region (i.e. greater $s_{\text {pop }}$ ) will attract more and more industry during a process of falling trade costs. Sooner or later all the industry will be concentrated in the larger region. This process is shown in figure 1 , where the share of industry in region $H$ is depicted against the freeness of trade where it 
is assumed that region $H$ is larger in terms of population.

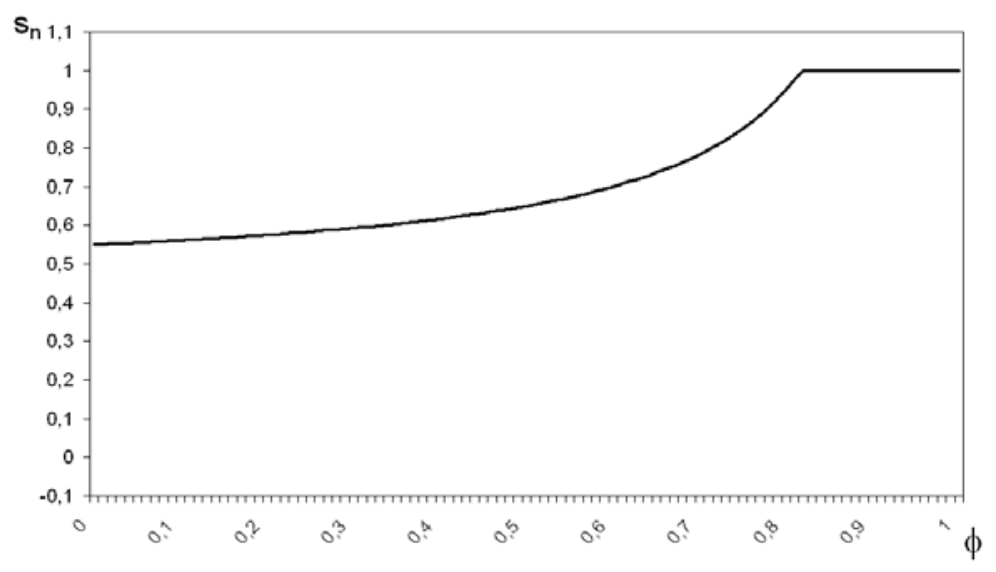

Figure 1: Bifurcation Diagram

Having the larger share of industry implies also a lower consumer price index and accordingly a higher real income. This can be seen by rewriting the price indices (8) of regions $H$ and $F$ where prices (7) have been inserted:

$$
\begin{aligned}
P_{H} & =\left(\frac{\sigma}{\sigma-1}\right)\left[X_{H} s_{n}+\phi X_{F}\left(1-s_{n}\right)\right]^{\frac{1}{1-\sigma}} n^{\frac{1}{1-\sigma}} \\
P_{F} & =\left(\frac{\sigma}{\sigma-1}\right)\left[X_{F}\left(1-s_{n}\right)+\phi X_{H} s_{n}\right]^{\frac{1}{1-\sigma}} n^{\frac{1}{1-\sigma}} .
\end{aligned}
$$

Considering only interior solution it follows from (16) that a higher share of industry in one region decreases its price index and increases the price index in the other region. However, the local share of industry increases with local infrastructure, therefore smaller regions with a lower share of expenditure can compensate their home market disadvantage by investing in infrastructure. For every combination of size asymmetry and trade freeness, there is one ratio of regional infrastructure that ensures an equal distribution of industry. Moreover, region $H$ attracts all industry if it provides an infrastructure level $X_{H}^{A g g}$, just as well as region $F$ does when providing $X_{F}^{A g g}$ :

$$
X_{H}^{A g g}=\frac{1-s_{p o p}\left(1-\phi^{2}\right)}{\phi} X_{F}, \quad X_{F}^{A g g}=\frac{s_{p o p}+\phi^{2}\left(1-s_{p o p}\right)}{\phi} X_{H}
$$


Taking the logarithm of price indices (16), we can express the impact of regional infrastructure in utility terms. Assuming interior solutions, that is $0<s_{n}<1$ we may further substitute for the long-run share of industry (15):

$$
\begin{aligned}
\ln \left(P_{H}\right) & =\frac{1}{1-\sigma} \ln \left[\frac{X_{H} X_{F} s_{p o p}\left(1-\phi^{2}\right)}{X_{F}-\phi X_{H}}\right]+A \quad \text { and } \\
\ln \left(P_{F}\right) & =\frac{1}{1-\sigma} \ln \left[\frac{X_{H} X_{F}\left(1-s_{p o p}\right)\left(1-\phi^{2}\right)}{X_{H}-\phi X_{F}}\right]+A, \\
& \text { with } A=\frac{1}{1-\sigma} \ln (n)+\ln \left(\frac{\sigma}{\sigma-1}\right) .
\end{aligned}
$$

These prices are only defined for $\chi>\phi$ and $1 / \chi>\phi$. This means, the higher the trade freeness the lower the potential infrastructure differences. Intuitively this restriction states that consumer prices of imported varieties (i.e. the producer price plus trade costs) have to be higher than the consumer price of locally produced varieties (i.e. the producer price). ${ }^{5}$ Infrastructure differences that imply a lower consumer price for imports than for local varieties would lead to full concentration of industry in the region with the better infrastructure, no matter what expenditure shares apply.

If all the industry is concentrated in region $j$, the price indices are from (16):

$$
\ln \left(P_{j}\right)=\frac{1}{1-\sigma} \ln \left[X_{j}\right]+A \quad \text { and } \quad \ln \left(P_{k}\right)=\frac{1}{1-\sigma} \ln \left[\phi X_{j}\right]+A, \quad k \neq j .
$$

In the following it will be analyzed how the distribution of industry in figure ?? changes if regions are allowed to compete with infrastructure.

\section{Decentralization}

First, we analyze a situation where the two regions act independently, which we call decentralization.

\footnotetext{
${ }^{5} \chi>\phi$ implies $c_{F} \tau>c_{H}$, thus $\hat{p}_{F} \tau>\hat{p}_{H} \cdot \frac{1}{\chi}>\phi$ implies $c_{H} \tau>c_{F}$, thus $\hat{p}_{H} \tau>\hat{p}_{F}$.
} 


\subsection{Infrastructure and Price Index}

It is crucial to the argument to illustrate the impact of infrastructure provision on the local price index, because this is the channel through which the indirect utility of a consumer is affected. Two distinct effects of infrastructure affect regions' welfare. First, a lower input coefficient obviously allows to produce more output for given input. Differentiating (16) with respect to infrastructure and keeping the share of industry constant yields:

\section{Direct local price index effect}

$$
\left.\frac{\partial \ln \left(P_{H}\right)}{\partial X_{H}}\right|_{\overline{s_{n}}}=\left(\frac{1}{1-\sigma}\right) \frac{1}{X_{H} s_{n}+\phi X_{F}\left(1-s_{n}\right)} s_{n}<0 .
$$

Since the regional price index decreases, citizens utility increases. Second, from (13) we know that capital returns increase in the quality of local infrastructure provided. A region therefore attracts industry, when investing in infrastructure. The increasing share of local firms again lowers the local consumer price index, because less goods have to be imported in order to consume the optimal consumption bundle. This means citizens will save on trade costs. Differentiating (16) with respect to the share of industry and (15) with respect to infrastructure yields:

\section{Indirect local price index effect}

$$
\frac{\partial \ln \left(P_{H}\right)}{\partial X_{H}}=\underbrace{\left(\frac{1}{1-\sigma}\right) \frac{X_{H}-\phi X_{F}}{X_{H} s_{n}+\phi X_{F}\left(1-s_{n}\right)} X_{F} \phi\left(\frac{s_{\text {pop }}}{\left(X_{F}-\phi X_{H}\right)^{2}}+\frac{\left(1-s_{\text {pop }}\right)}{\left(X_{H}-\phi X_{F}\right)^{2}}\right)}_{\frac{\partial \ln \left(P_{H}\right)}{\partial s_{n}}}<0 .
$$

The first part of this effect $\left|\frac{\partial \ln \left(P_{H}\right)}{\partial s_{n}}\right|$ decreases with trade freeness $\phi$, whereas the second part $\left|\frac{\partial s_{n}}{\partial X_{H}}\right|$ increases. This means for high trade freeness, it is not as important for consumers to have firms located in their home regions. However, firms get more footloose when trade costs fall, which implies they are more easily attracted by infrastructure. This results from the fact that the home-market effect, which ties firms to the larger market, looses some of its strength. Overall the indirect effect increases with trade freeness.

For prohibitively high trade costs, that is $\phi=0$, there is no indirect effect, because firms will choose their location only with respect to the exogenous home-market size. In 
this case infrastructure does not have any impact on the long-run location of firms. For infinitely low trade costs, that is $\phi=1$, the restriction described above does not allow for interior solutions. A corner solution with one region not providing any infrastructure has to apply.

The amount of industry one region attracts, the other will loose. This is because the number of firms in the economy as a whole is given by the stock of capital $n=K^{W}=$ $K_{H}+K_{F}$. Therefore each region exerts a negative effect on the utility of foreigners, when investing in local infrastructure. Furthermore in uncoordinated behavior each region does not consider this indirect negative effect it has on the other region, when lowering the regional consumer price index. A negative externality evolves, which gains relevance for welfare because of monopolistic competition.

The public good characteristics of infrastructure generates an additional, counteracting externality which becomes relevant if the trade freeness is sufficiently high. For low trade costs it might be cheaper to import manufactured goods than bearing the costs of providing enough infrastructure to have a decent share of manufacturing firms located in the respective region. Therefore one of the two regions may decide not to provide any infrastructure at all and free-ride on the expenses of the other region. The same free-riding externality occurs if regions are very asymmetric in terms of population and infrastructural endowments. In this case it is very expensive for the smaller or less endowed region to attract industry and it may decide to better import and use the foreign infrastructure. Which of the two externalities dominates, the negative or the positive, depends crucially on the trade freeness and the initial distribution of industry as will be shown in the following.

\subsection{Fiscal Competition Equilibria}

Region will maximize welfare of their citizens in the long run by local infrastructure investment financed through income taxes subject to the residence principle. Thereby, each region takes infrastructure endowment in the other region as given. Since wages are 
equal to one and capital returns in the long run equilibrium are the same for all capital owners, the objective of region $j$ can be written as

$$
\max _{X_{j}} \quad W_{j} \equiv L_{j}+K_{j} \bar{R}-X_{j}-\left(K_{j}+L_{j}\right) \mu \ln \left(P_{j}\right) \quad \text { s.t. (15). }
$$

In a Nash equilibrium, both regions solve simultaneously the respective optimization problem.

In order to obtain general analytic results, we assume a symmetric distribution of population in the remaining part of this section: $s_{p o p}=1 / 2$. Later on, we will numerically solve for equilibria when population is asymmetrically distributed.

Depending on trade costs, fiscal competition may lead either to interior equilibria and dispersion of industry or to corner equilibria and agglomeration, as the following proposition states.

Proposition 1 (a) A symmetric locally stable Nash equilibrium

$$
X_{H}=X_{F}=\frac{\mu N}{2(1-\phi)(\sigma-1)}>0 \quad \text { with } \quad s_{n}=\frac{1}{2}
$$

exists if and only if $\phi \leq 0.1748$.

(b) No Nash equilibrium exists if and only if $0.1748<\phi<0.2832$.

(c) Corner Nash equilibra with

$$
X_{H}=\frac{\mu N}{2(\sigma-1)}, X_{F}=0, s_{n}=1 \quad \text { or } \quad X_{F}=\frac{\mu N}{2(\sigma-1)}, X_{H}=0, s_{n}=0
$$

exist if and only if $\phi \geq 0.2832$.

\section{Proof. See Appendix A.}

In the symmetric Nash equilibrium, the provided level has the expected correlations. It increases with $\mu$, because manufactured goods gain more weight in the individuals' preferences. The indirect effect, and accordingly the competition for industrial firms, gets the stronger the higher $\phi$. Therefore, the provided level increases in trade freeness, 
too. The elasticity of substitution $\sigma$ has a negative effect on the equilibrium provision of infrastructure, because the output elasticity of infrastructure $1 /(\sigma-1)$ decreases with $\sigma$.

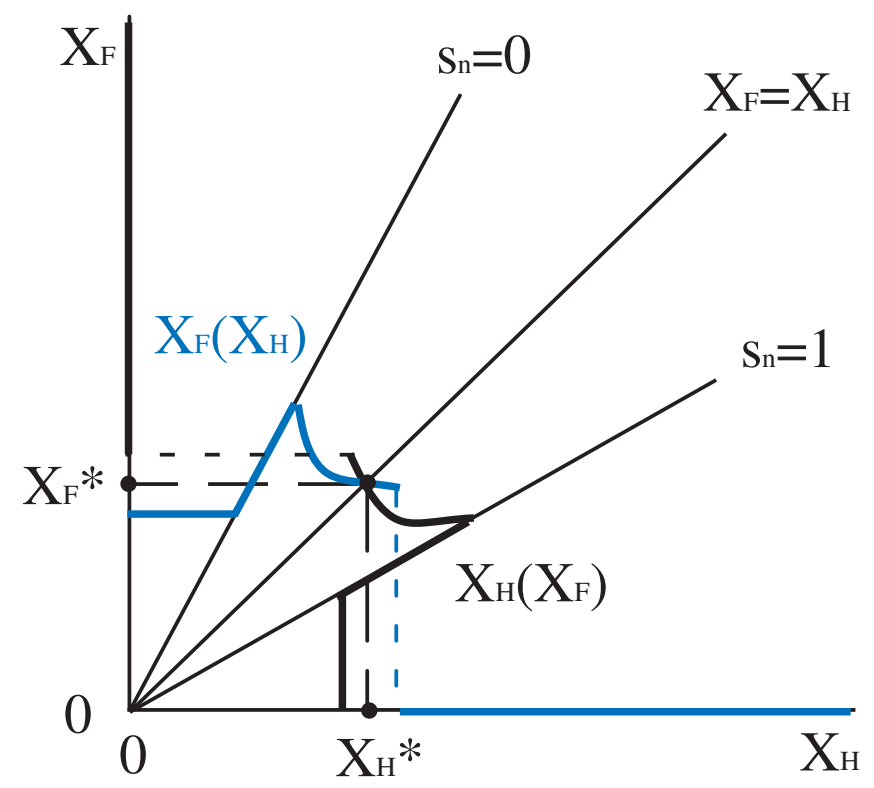

Figure 2: Interior Nash Equilibrium at Low Trade Freeness

In this case, free-riding will not occur, because the trade costs are too high to waive local industry. In contrast, the regions prefer to invest in infrastructure in order to attract industry from the foreign region.

Corner Nash equilibria particularly require that the periphery does not prefer to deviate. It may prefer to deviate from the corner solution of zero infrastructure provision if any positive value of infrastructure provision exists that ensures a higher utility than the corner solution does. There are two possible candidates that may be beneficial for the periphery. It either provides the optimal level for a interior solution or it provides a very high level of infrastructure that attracts all industry from the core.

Corner solutions only exist if trade freeness is sufficiently high. The intuition for this finding is that both regions try to free-ride on the expenses of the other region if the trade costs are sufficiently low, since the costs of setting up local industry exceed the costs of 
importing manufactured goods from the foreign region.

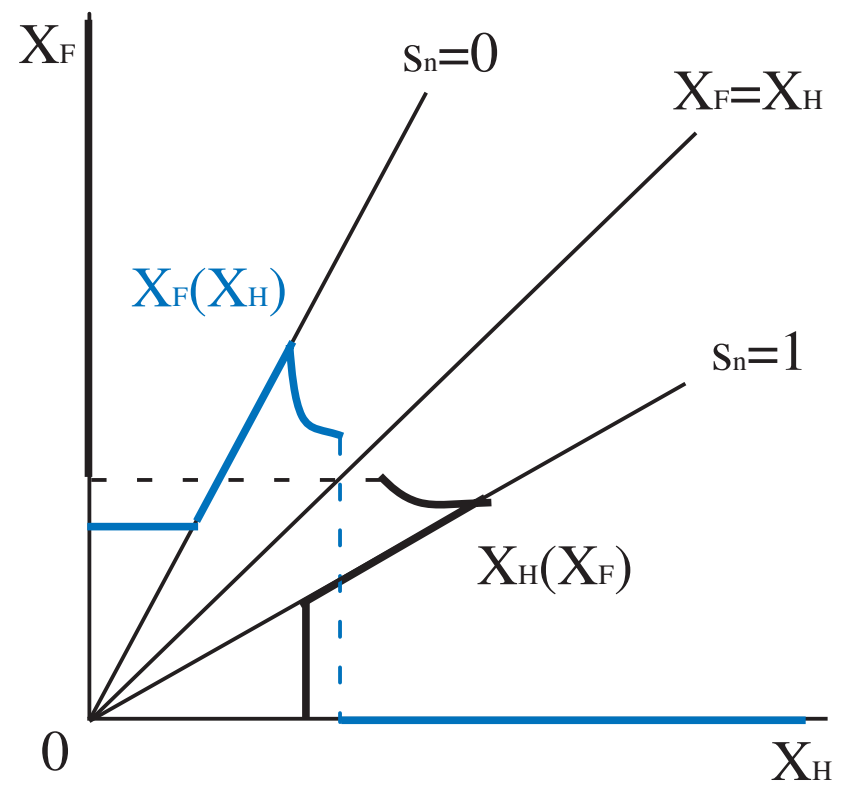

Figure 3: Non-Existence of Nash Equilibrium at Medium Trade Freeness

In decentralized equilibrium we may distinguish three scenarios, with respect to the trade freeness. First, if trade costs are very high, i.e., if $\phi<0.1748$, only a stable symmetric Nash equilibrium with disperion of industry exists. Second, for medium trade costs no Nash equilibrium exists at all. Third, if trade freeness is high, i.e., if $\phi>0.2832$, only corner Nash equilibria with a core-periphery pattern occur. The first case is depicted in figure 2 , the second in figure 3 , the third in figure 4 . These figures show the reaction curves of both regions and - provided that they exist - their intersection points, the Nash equilibria. Furthermore, full agglomeration lines where the entire industry is located in either region are also shown. Unsurprisingly, regions do not increase infrastructure investment further when the industry is already completely located on their territory. The periphery without any industry does not invest at all. Even stronger, a region would not invest in infrastructure, if the other region provides a large quantity of public goods, since the induced industry share were too low.

The shape of the reaction curves can be easily explained. Starting at low infrastructure investment of region $F$, region $H$ invests as much as necessary to attract all manufacturing 
firms and to become the core. When the other region increases investment further, region $H$ must also increase investment in order to prevent capital flight. If a certain investment level of region $F$ is achieved, this strategy becomes too costly. Region $H$ now reduces investment, leading to industry dispersion. A further increase in region $F$ 's investment ultimately exterminates any incentive to supply infrastructure. As a consequence, region $H$ does not supply infrastructure at all. For region $F$, the same reasoning applies. As can be seen from the figures, the higher trade freeness is, the smaller the area is where both regions supply infrastructural goods and where industry is dispersed.

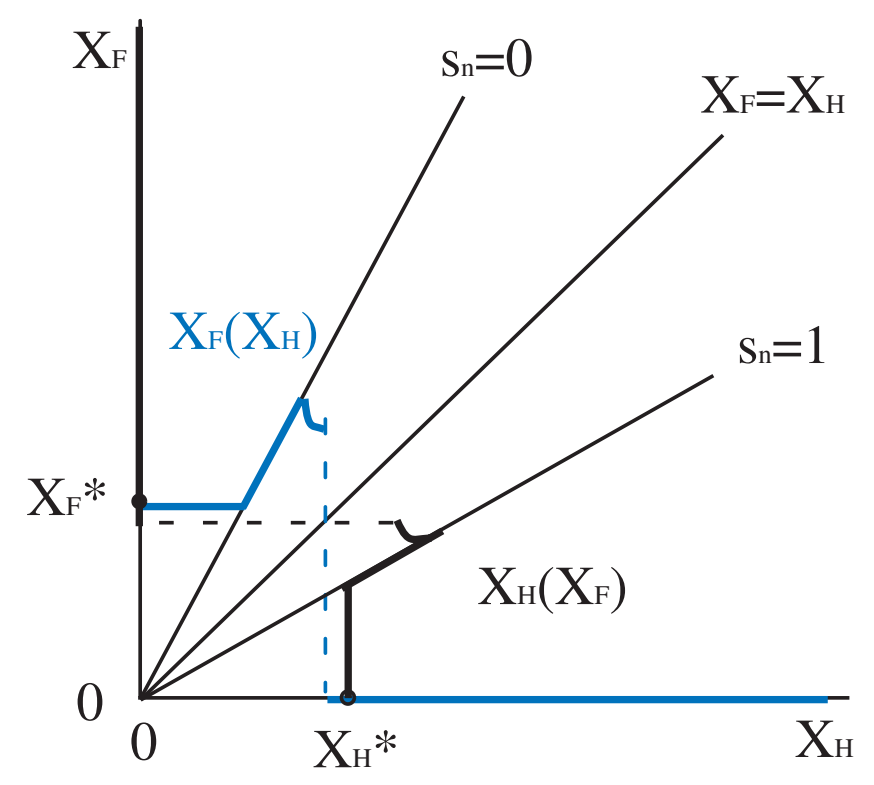

Figure 4: Corner Nash Equilibria at High Trade Freeness

For low trade freeness (figure 2), reactions curves intersect once in the interior, for medium trade freeness never (figure 3), for high trade freeness (figure 4) two times at the axes. Furthermore, since in an interior equilibrium the reaction curve of region $H$ is steeper than the reaction curve of region $F$, this equilibrium is locally stable, i.e., adjustment along the reaction curves ultimately leads to the equilibrium. 


\section{Centralization}

A central government endowed with fiscal authorities may levy taxes on both regions symmetrically but distribute infrastructure asymmetrically. Furthermore, the central government internalizes externalities regions impose on each other. Again workers and capital owners in both regions are taxed in order to finance infrastructure. The objective of the federal government is to maximize the sum of workers' utility in both regions:

$$
\begin{aligned}
\max _{X_{H}, X_{F}} W \equiv & L_{H}+L_{F}+n \bar{R}-X_{H}-X_{F} \\
& \quad-\left(K_{H}+L_{H}\right) \mu \ln \left(P_{H}\right)-\left(K_{F}+L_{F}\right) \mu \ln \left(P_{F}\right) \quad \text { s.t. (15). }
\end{aligned}
$$

To solve this problem, we assume again equally sized regions,i.e. $s_{\text {pop }}=1 / 2$.

Proposition 2 Symmetric distribution of infrastructure is optimal for low trade freeness, i.e., if $\phi<7-4 \sqrt{3} \approx 0.0717$. Otherwise, a corner solution with either all infrastructure in region $H$ or region $F$ is optimal. Independent of trade costs, the optimum aggregate infrastructure investment is

$$
X_{H}+X_{F}=\frac{\mu N}{\sigma-1}
$$

\section{Proof. See Appendix B.}

For high trade freeness, manufacturing goods produced in one region can be consumed in both regions at low costs. Hence the federal government concentrates infrastructure in one region in order to maximize the aggregate productivity in the manufacturing sector. In this case the gain in aggregate productivity is higher than the rise of expenses on trade costs.

For low trade freeness, the federal government distributes infrastructure equally with the consequence of low aggregate productivity in order to minimize overall trade costs. The savings on trade costs due to the equalized distribution of manufacturing plants dominates the potential gain in aggregate productivity.

Comparing optimal infrastructure investment with the outcome from fiscal competition, differences occur with respect to the level and the distribution of infrastructure 
investment depending on trade costs. A comparison of the critical trade costs values given in the pervious propositions yields immediately:

Proposition 3 (a) For medium trade freeness, i.e., for $0.1748<\phi<0.2832$, the allocation of infrastructure cannot be determined consistently by decentral authorities.

(b) A decentralized federation oversupplies public infrastructure if trade costs are high, i.e., if $\phi<0.1748$ (where infrastructure investment is fully equalized). For high trade freeness, i.e., for $\phi>0.2832$, decentralization leads to undersupply.

(c) When trade costs fall, a decentralized federation changes too late from full equalization of infrastructure investment and dispersed industry locations to a core-periphery pattern.

For medium trade freeness, both jurisdictions would alternately overbid and underbid each other. As a result, a decentralized federation does not even come to a solution to the allocation problem. For more extreme trade costs, decentral authorities provide consistently infrastructural goods, but never efficiently.

The central government provides always $X_{H}+X_{F}=\mu N /(\sigma-1)$ on aggregate. However, in the decentralized case each of the two regions provides $\mu N /[2(\sigma-1)(1-\phi)]$ if the full equalization equilibrium applies. If a core-periphery pattern arises, the core region provides infrastructure $\mu N /[2(\sigma-1)]$. The intuition for those results are as follows: For low trade freeness it is crucial to have industry located nearby, therefore the negative externality from competing for industry dominates the positive externality due to the public input characteristic of infrastructure and the regions overprovide infrastructure in decentralized equilibrium. As the trade costs fall below a critical value, importing manufactured goods becomes cheap enough to waive local industry. This strategy allows to save the costs of setting up infrastructure by indirectly using the foreign one. Using infrastructure without contributing to the costs of providing it represents a free-riding externality, which now leads to underprovision. Furthermore, if the industry is located in one region, the core is able to skim off agglomeration rents, and thus reduces its effort to reduce production costs. 
Comparing dezentralization and centralization with respect to the distribution of infrastructure an inefficiency arises for the range of trade freeness between 0.0717 and 0.2832 , because corner solutions occur in the centralized economy already for lower trade freeness than in the decentralized economy. Choosing a corner solution without local industry a single region benefits from increasing aggregate productivity only to the extent weighted by the trade freeness. Therefore, the productivity gain it takes into account is smaller than the aggregate productivity gain the federation faces as a whole. Moreover, the increase in trade costs of the region that looses all industry is higher than the average increase in trade costs, since the other saves trade costs. Both effects imply that the federal government chooses corner solutions already for a lower trade freeness than the single regions do in Nash equilibrium.

\section{Extensions}

Assuming symmetry and pure public goods greatly simplifies the analysis, but our results are much more general. They will qualitatively hold in reasonably more complex circumstances.

\subsection{Asymmetric Regions}

Asymmetry in population size does not change mechanisms and results fundamentally. Although it is not possible to obtain analytical results, by way of numerical analysis it can be shown that the comparison of decentral and central states leads to similar results as in a state with equally sized regions. First, for low trade freeness, in a decentralized federation both regions provide public infrastructure and the aggregate level of investment is too high. For high trade freeness, decentralization leads again to undersupply. Second, in the process of trade integration a decentralized federation changes too late from dispersion of infrastructure investment and industry locations to a core-periphery pattern. 
However, asymmetry is an additional source of inefficiency. For low trade freeness, competition for mobile firms forces both the smaller and the larger region strongly to supply public infrastructure. As a result, the difference in public investment in an interior Nash equilibrium is too small. A central planer would increase investment in the larger region and simultaneously reduce expenditure in the smaller region.

\subsection{Congestion Costs}

Of course, there could be congestion costs that act against the efficiency of agglomeration. One possibility to take those into account is to assume that infrastructure entails usage costs that increase in the local amount of firms (Sinn, 1997). This relationship can be defined by a cost function:

$$
\operatorname{Cost}\left(I_{H}\right)=\left[1+\alpha\left(\frac{s_{n}}{0.5}-1\right)\right] I_{H} \quad \text { and } \operatorname{Cost}\left(I_{F}\right)=\left[1+\alpha\left(\frac{\left(1-s_{n}\right)}{0.5}-1\right)\right] I_{F},
$$

where $\alpha, 0 \leq \alpha \leq 1$, represents the parameter of congestion. For $\alpha=0$ as well as for symmetric industry distribution $\left(s_{n}=0.5\right)$ there is no congestion, the price of infrastructure provision remains unity as before. The higher $\alpha$ and the larger the asymmetry of industry distribution, the stronger the congestion. For full agglomeration the price of infrastructure in the core region becomes $1+\alpha$. The implied utility for symmetric distribution of infrastructure is the same as in the absence of congestion. Assuming again that regions are of the same size, welfare for full agglomeration in region $H$ changes to:

$$
W_{\text {Agg }}=L_{H}+L_{F}+n \bar{R}-(1+\alpha) X_{H}-\left(K_{H}+L_{H}\right) \mu \ln \left(P_{H}\right)-\left(K_{F}+L_{F}\right) \mu \ln \left(P_{F}\right)
$$

Comparing welfare without and with congestion, one can easily show that the critical value of trade freeness where agglomeration becomes efficient increases with $\alpha$.

Considering the Nash Equilibrium congestion costs entail an additional externality. While the marginal utilities of infrastructure in both regions are not affected by the congestion costs, the marginal costs of infrastructure provision are increasing in the stock of regional infrastructure and the congestion parameter $\alpha$. Hence, for low trade freeness the 
pressure to convergence in infrastructure levels is strengthened. However for sufficiently high trade freeness one may still expect corner solutions, i.e. full agglomeration, to arise. When deciding on whether to provide infrastructure or not a region compares the cost savings of not providing infrastructure to the utility loss of not having local industry and accordingly having to import all industrial goods. Compared to the scenario without congestion costs the costs savings have risen whereas the utility loss has not changed. Hence, corner solutions may occur for lower trade freeness than necessary for corner solutions without congestion costs. Regarding the efficiency of aggregate infrastructure provision the resulting overprovision in case of low trade freeness may be alleviated, since a region exerts not only a negative effect on the other region when investing in infrastructure by attracting industry but also a positive effect by decreasing the costs of infrastructure and accordingly the tax burden in the foreign region. The result of an underprovision in case of low trade-freeness, however, is still valid, since congestion costs do not arise in the periphery where all industry has left to the core. Obviously, the assumption of congestion costs may only act as an additional externality as long as both regions have some local industry that is as long as interior solutions arise.

\section{Conclusion}

Global markets become more and more integrated and trade costs are falling. We have shown that this phenomenon alters significantly the implications of fiscal competition. When trade costs are sufficiently low, it becomes favorable for regions to import industrial goods instead of providing infrastructure. Thus some regions may prefer to quit the competition for industry by providing better infrastructure. Those regions become voluntarily the periphery and specialize in the agricultural sectors. However, this free-riding behavior of some regions results in a inefficiently low level of aggregate infrastructure whereas the asymmetric distribution of infrastructure and industry is desirable from the welfare perspective. 
Since externalities arise as long as trade is possible a centralized provision of infrastructure is welfare-improving. For low trade costs this means that the overall level of infrastructure should be subsidized. Thus, our model implies that regional policies should subsidize infrastructure in core regions in order to achieve the efficient level of aggregate infrastructure.

Our model focuses on the effects of fiscal competition on infrastructure provision and industrial distribution. It neglects all effects of information asymmetries between central and decentral authorities which would make the case for decentralization. Moreover, our model features only one industrial sector with industry-specific infrastructure. Our results could be translated into a world with several industrial branches where efficient agglomeration means that various industrial sectors cluster in different regions. This is a tendency we observe in federations all over the world. 


\section{Appendix}

\section{A Proof of Proposition 1}

We analyze first candidates for interior Nash equilibria. From (22) we get for $s_{\text {pop }}=1 / 2$ and $0<s_{n}<1$ the following first-order conditions

$$
\begin{aligned}
1 & =\frac{\mu N}{2(\sigma-1)} \frac{X_{F}}{X_{H}\left(X_{F}-\phi X_{H}\right)}, \\
1 & =\frac{\mu N}{(\sigma-1)} \frac{X_{H}}{X_{F}\left(X_{H}-\phi X_{F}\right)},
\end{aligned}
$$

with reaction functions

$$
\begin{aligned}
& X_{H_{1,2}}=\frac{X_{F}(\sigma-1) \pm \sqrt{X_{F}(\sigma-1)\left[X_{F}(\sigma-1)-2 \mu \phi N\right]}}{2 \phi(\sigma-1)} \\
& X_{F_{1,2}}=\frac{X_{H}(\sigma-1) \pm \sqrt{X_{H}(\sigma-1)\left[X_{H}(\sigma-1)-2 \mu \phi N\right]}}{2 \phi(\sigma-1)}
\end{aligned}
$$

Thus, the potential equilibria in the interior are

$$
\begin{gathered}
X_{H_{1}}=X_{F_{1}}=\frac{\mu N}{2(1-\phi)(\sigma-1)} \\
X_{H_{2}}=\frac{\mu N}{(\sigma-1)}\left(\frac{1+\phi+\sqrt{1-2 \phi-3 \phi^{2}}}{4 \phi(\phi+1)}\right), X_{F_{2}}=\frac{\mu N}{(\sigma-1)}\left(\frac{1}{1+\phi+\sqrt{1-2 \phi-3 \phi^{2}}}\right), \\
X_{H_{3}}=\frac{\mu N}{(\sigma-1)}\left(\frac{1+\phi-\sqrt{1-2 \phi-3 \phi^{2}}}{4 \phi(\phi+1)}\right), X_{F_{3}}=\frac{\mu N}{(\sigma-1)}\left(\frac{1}{1+\phi-\sqrt{1-2 \phi-3 \phi^{2}}}\right) .
\end{gathered}
$$

Note that the second and third solutions are only defined for $\phi \leq 1 / 3$. Calculating the second derivatives and the cross derivatives gives

$$
\begin{gathered}
\frac{\partial^{2} W_{H}}{\partial X_{H}^{2}}=\left[\frac{\mu N}{2(1-\sigma)}\right] \frac{X_{F}\left(X_{F}-2 \phi X_{H}\right)}{X_{H}^{2}\left(X_{F}-\phi X_{H}\right)^{2}}, \quad \frac{\partial^{2} W_{F}}{\partial X_{F}^{2}}=\left[\frac{\mu N}{2(1-\sigma)}\right] \frac{X_{H}\left(X_{H}-2 \phi X_{F}\right)}{X_{F}^{2}\left(X_{H}-\phi X_{F}\right)^{2}}, \\
\frac{\partial^{2} W_{H}}{\partial X_{H} \partial X_{F}}=\frac{\mu N \phi}{2(1-\sigma)\left(X_{F}-\phi X_{H}\right)^{2}}, \quad \frac{\partial^{2} W_{F}}{\partial X_{F} \partial X_{H}}=\frac{\mu N \phi}{2(1-\sigma)\left(X_{H}-\phi X_{F}\right)^{2}} .
\end{gathered}
$$

For $X_{F}=X_{H}$, the second-order condition $\partial^{2} W_{j} / \partial X_{j}^{2} \leq 0$ is only fulfilled for $\phi \leq$ $1 / 2$. For the asymmetric candidates, the second-order conditions $\partial^{2} W_{H} / \partial X_{H}^{2} \leq 0$ and $\partial^{2} W_{F} / \partial X_{F}^{2} \leq 0$ require $4 \phi^{2}+2 \phi-1 \geq 0$, i.e. $\phi \geq 0.309017$. 
The symmetric equilibrium is locally stable if the reaction curve $X_{H}\left(X_{F}\right)$ is steeper than $X_{F}\left(X_{H}\right)$, i.e., if

$$
-\frac{\partial^{2} W_{H} / \partial X_{H}^{2}}{\partial^{2} W_{H} /\left(\partial X_{H} \partial X_{F}\right)}<-\frac{\partial^{2} W_{F} /\left(\partial X_{F} \partial X_{H}\right)}{\partial W_{F} / \partial X_{F}^{2}} \Leftrightarrow \frac{2 \phi-1}{\phi}<\frac{\phi}{2 \phi-1},
$$

which is satisfied for $\phi<1 / 3$.

It can be easily shown that for both asymmetric solutions there exists one region which would gain from abandoning public infrastructure investment completely. Thus, the asymmetric solutions do not be Nash equilibria.

When one single region deviates from the symmetric solution and does not provide public infrastructure, the gain for this region is

$$
\frac{\mu N\{1+(1-\phi) \ln (\phi)-(1-\phi) \ln [(1+\phi) / 2]\}}{2(1-\phi)(\sigma-1)},
$$

which is positive if and only if $\phi>0.1748$. A single upwards deviation, i.e., a strong increase in investment which makes the deviating region core, pays only if $\phi>0.4492$. Hence, already for $\phi>0.1748$ a symmetric Nash equilibrium does not exist.

Now, we consider corner solutions. If one region, say region $F$, does not supply infrastructural goods, region $H$ maximizes regional welfare $W_{H}$ by choosing $X_{H}=\mu N /[2(\sigma-$ 1)] (which fulfills the second-order conditions for $H$ ). If region $F$ deviates by supplying infrastructure according to the reaction curve given above it gains

$$
\frac{\mu N}{4 \phi(\sigma-1)}\left\{\sqrt{1-4 \phi}-1-\phi \ln (4)-2 \phi \ln (\phi)+2 \phi \ln \left[\frac{\left(\phi^{2}-1\right)(\sqrt{1-4 \phi}-1)}{\phi(\sqrt{1-4 \phi}+1)}\right]\right\},
$$

which is positive if and only if $\phi<0.25$. If region $F$ deviates upwards, i.e., if it supplies $X_{F}^{A g g}$ which makes it the core, it gains

$$
-\frac{\mu N}{4 \phi(\sigma-1)}\left[1+\phi^{2}+2 \phi \ln (2 \phi)-2 \phi \ln \left(\frac{1+\phi^{2}}{\phi}\right)\right]
$$

which is positive for $0.2203<\phi<0.2832$. Hence, for $\phi<0.2832$ a corner Nash equilibrium does not exist.

As a consequence, for $0.1748<\phi<0.2832$ single deviations rule out any equilibrium. 


\section{B Proof of Proposition 2}

In order to solve the optimization problem (25) for $s_{\text {pop }}=1 / 2$, we determine separately interior solutions and corner solutions, compare the implied welfare levels, and, finally, choose the strategy which leads to the highest welfare level.

For infrastructure investment that implies $0<s_{n}<1$, the first-order conditions are

$$
\begin{aligned}
1 & =\frac{\mu N}{\sigma-1} \frac{1}{X_{H}}\left(2+\frac{X_{H} \phi}{X_{F}-\phi X_{H}}-\frac{X_{H}}{X_{H}-\phi X_{F}}\right), \\
1 & =\frac{\mu N}{\sigma-1} \frac{1}{X_{F}}\left(2+\frac{X_{F} \phi}{X_{H}-\phi X_{F}}-\frac{X_{F}}{X_{F}-\phi X_{H}}\right) .
\end{aligned}
$$

There are exactly three solutions for regional infrastructure investments. One solution that implies full equalization of regional infrastructure, that is a ratio $\chi_{1}=1$ and absolute levels:

$$
X_{H_{1}}=X_{F_{1}}=\frac{\mu N}{2(\sigma-1)} .
$$

The trace and the detminant for this symmetric solution are

$$
\begin{aligned}
\operatorname{trace}_{\chi_{1}} & =-\frac{4(\sigma-1)[1+\phi(\phi-4)]}{\mu N(1-\phi)^{2}} \\
\operatorname{det}_{\chi_{1}} & =\frac{4(\sigma-1)^{2}[1+\phi(\phi-6)]}{\mu^{2} N^{2}(1-\phi)^{2}} .
\end{aligned}
$$

Hence, for $\phi<3-2 \sqrt{2} \approx 0.1715$ the determinant is positive (and the trace negative), and, therefore, this symmetric solution is a maximum.

Beside this symmetric solution, there are two asymmetric solutions that imply regional infrastructure ratios $\chi_{2,3}$, with $\chi_{3}<\chi_{1}<\chi_{2}$, which are only defined for $\phi \leq 3-2 \sqrt{2}$. However, using continuity one can easily show that those two solutions are minima.

In order to obtain candidates for corner solutions, we set without loss of generality $X_{F}$ to zero. This implies a first-order condition for $X_{H}$

$$
\frac{\mu N}{X_{H}(\sigma-1)}-1=0
$$

and, thus, $X_{H}=\mu N /(\sigma-1)$ (the second-order condition is obviously fulfilled). 
The difference in welfare between the corner solution and an interior symmetric allocation of infrastructure is

$$
\frac{\mu N}{2(\sigma-1)}[\ln (16)+\ln (\phi)-2 \ln (1+\phi)]
$$

which is positive if and only if $\phi>7-4 \sqrt{3}$.

\section{References}

[1] Andersson, F. and R. Forslid (2003). Tax competition and economic geography. Journal of Public Economic Theory 5: 279-303.

[2] Baldwin, R.E., Forslid, R., Martin, P., Ottaviano, G.I.P. and F. Robert-Nicoud (2003). Economic Geography and Public Policy. Princeton University Press, Princeton, NJ.

[3] Baldwin, R.E. and P. Krugman (2004). Agglomeration, integration and tax harmonisation. European Economic Review 48: 1-23.

[4] Borck, R. and M. Pflüger (2006). Agglomeration and tax competition. European Economic Review 50: 647-668.

[5] Dixit, A. and J.E. Stiglitz (1977). Monopolistic competition and optimum product diversity. American Economic Review 67: 297-308.

[6] Dupont, V. and P. Martin (2006). Subsidies to poor regions and inequalities: some unpleasant arithmetic. Journal of Economic Geography 6: 223-240.

[7] European Commission (2001). Second Report on Economic and Social Cohesion. EU Publications Office. Bruxelles.

[8] Fujita, M., Krugman, P. and A.J. Venables (1999). The Spatial Economy. Cities, Regions, and International Trade. MIT Press, Cambridge, MA. 
[9] Kind, H.J., Knarvik, K.H.M. and G. Schjelderup (2000). Competing for capital in a lumpy world. Journal of Public Economics 78: 253-274.

[10] Krugman, P. (1991). Increasing returns and economic geography. Journal of Political Economy 99: 483-499.

[11] Ludema, R.D. and I. Wooton (2000). Economic geography and the fiscal effects of regional integration. Journal of International Economics 52: 331-357.

[12] Martin, P. (1999). Public policies, regional inequalities and growth. Journal of Public Economics 73: 85-105.

[13] Martin, P. and G.I.P. Ottaviano (1999). Growing locations: Industry location in a model of endogenous growth, European Economic Review 43. 281-302.

[14] Martin, P. and C.A. Rogers (1995). Industrial location and public infrastructure. Journal of International Economics 39: 335-51.

[15] Noiset, L. (1995). Pigou, Tiebout, property taxation and the underprovision of local public goods: comment, Journal of Urban Economics 38: 312-16.

[16] Pflüger, M. (2004). A simple, analytically solvable Chamberlinian agglomeration model. Regional Science and Urban Economics 34: 565-573.

[17] Sinn, H.-W. (1997). The selection principle and market failure in systems competition, Journal of Public Economics 66, 247-74.

[18] Zodrow, G.R., and P. Mieszkowski (1986). Pigou, Tiebout, property taxation and the underprovision of local public goods, Journal of Urban Economics 19: 356-70. 


\section{CESifo Working Paper Series}

for full list see www.cesifo-group.org/wp

(address: Poschingerstr. 5, 81679 Munich, Germany, office@cesifo.de)

2024 Erkki Koskela and Ronnie Schöb, Tax Progression under Collective Wage Bargaining and Individual Effort Determination, June 2007

2025 Jay Pil Choi and Marcel Thum, The Economics of Politically Connected Firms, June 2007

2026 Jukka Pirttilä and Roope Uusitalo, Leaky Bucket in the Real World: Estimating Inequality Aversion Using Survey Data, June 2007

2027 Ruslan Lukach, Peter M. Kort and Joseph Plasmans, Strategic R\&D with Knowledge Spillovers and Endogenous Time to Complete, June 2007

2028 Jarko Fidrmuc, Neil Foster and Johann Scharler, Labour Market Rigidities, Financial Integration and International Risk Sharing in the OECD, June 2007

2029 Bernardina Algieri and Thierry Bracke, Patterns of Current Account Adjustment Insights from Past Experience, June 2007

2030 Robert Dur and Hein Roelfsema, Social Exchange and Common Agency in Organizations, June 2007

2031 Alexander Libman and Lars P. Feld, Strategic Tax Collection and Fiscal Decentralisation: The Case of Russia, June 2007

2032 Øystein Foros, Hans Jarle Kind and Greg Shaffer, Resale Price Maintenance and Restrictions on Dominant Firm and Industry-Wide Adoption, June 2007

2033 Jan K. Brueckner and Kurt Van Dender, Atomistic Congestion Tolls at Concentrated Airports? Seeking a Unified View in the Internalization Debate, June 2007

2034 Viet Do and Ngo Van Long, International Outsourcing under Monopolistic Competition: Winners and Losers, June 2007

2035 Nadia Fiorino and Roberto Ricciuti, Determinants of Direct Democracy, June 2007

2036 Burkhard Heer and Alfred Maussner, Inflation and Output Dynamics in a Model with Labor Market Search and Capital Accumulation, June 2007

2037 Konstantinos Angelopoulos, Jim Malley and Apostolis Philippopoulos, Public Education Expenditure, Growth and Welfare, June 2007

2038 Maarten Bosker, Steven Brakman, Harry Garretsen and Marc Schramm, Adding Geography to the New Economic Geography, June 2007 
2039 Steffen Henzel, Oliver Hülsewig, Eric Mayer and Timo Wollmershäuser, The Price Puzzle Revisited: Can the Cost Channel Explain a Rise in Inflation after a Monetary Policy Shock?, July 2007

2040 Rosario Crinò, Service Offshoring and White-Collar Employment, July 2007

2041 Carsten Hefeker and Michael Neugart, Labor Market Regulation and the Legal System, July 2007

2042 Bart Cockx and Muriel Dejemeppe, Is the Notification of Monitoring a Threat to the Unemployed? A Regression Discontinuity Approach, July 2007

2043 Alfons J. Weichenrieder, Profit Shifting in the EU: Evidence from Germany, July 2007

2044 Annika Alexius and Bertil Holmlund, Monetary Policy and Swedish Unemployment Fluctuations, July 2007

2045 Axel Dreher, Jan-Egbert Sturm and Jakob de Haan, Does High Inflation Cause Central Bankers to Lose their Job? Evidence Based on a New Data Set, July 2007

2046 Guglielmo Maria Caporale and Luis A. Gil-Alana, Long Run and Cyclical Dynamics in the US Stock Market, July 2007

2047 Alessandro Balestrino, It is a Theft but not a Crime, July 2007

2048 Daniel Becker and Michael Rauscher, Fiscal Competition in Space and Time: An Endogenous-Growth Approach, July 2007

2049 Yannis M. Ioannides, Henry G. Overman, Esteban Rossi-Hansberg and Kurt Schmidheiny, The Effect of Information and Communication Technologies on Urban Structure, July 2007

2050 Hans-Werner Sinn, Please Bring me the New York Times - On the European Roots of Richard Abel Musgrave, July 2007

2051 Gunther Schnabl and Christian Danne, A Role Model for China? Exchange Rate Flexibility and Monetary Policy in Japan, July 2007

2052 Joseph Plasmans, Jorge Fornero and Tomasz Michalak, A Microfounded Sectoral Model for Open Economies, July 2007

2053 Vesa Kanniainen and Panu Poutvaara, Imperfect Transmission of Tacit Knowledge and other Barriers to Entrepreneurship, July 2007

2054 Marko Koethenbuerger, Federal Tax-Transfer Policy and Intergovernmental PreCommitment, July 2007

2055 Hendrik Jürges and Kerstin Schneider, What Can Go Wrong Will Go Wrong: Birthday Effects and Early Tracking in the German School System, July 2007 
2056 Bahram Pesaran and M. Hashem Pesaran, Modelling Volatilities and Conditional Correlations in Futures Markets with a Multivariate t Distribution, July 2007

2057 Walter H. Fisher and Christian Keuschnigg, Pension Reform and Labor Market Incentives, July 2007

2058 Martin Altemeyer-Bartscher, Dirk T. G. Rübbelke and Eytan Sheshinski, Policies to Internalize Reciprocal International Spillovers, July 2007

2059 Kurt R. Brekke, Astrid L. Grasdal and Tor Helge Holmås, Regulation and Pricing of Pharmaceuticals: Reference Pricing or Price Cap Regulation?, July 2007

2060 Tigran Poghosyan and Jakob de Haan, Interest Rate Linkages in EMU Countries: A Rolling Threshold Vector Error-Correction Approach, July 2007

2061 Robert Dur and Klaas Staal, Local Public Good Provision, Municipal Consolidation, and National Transfers, July 2007

2062 Helge Berger and Anika Holler, What Determines Fiscal Policy? Evidence from German States, July 2007

2063 Ernesto Reuben and Arno Riedl, Public Goods Provision and Sanctioning in Privileged Groups, July 2007

2064 Jan Hanousek, Dana Hajkova and Randall K. Filer, A Rise by Any Other Name? Sensitivity of Growth Regressions to Data Source, July 2007

2065 Yin-Wong Cheung and Xing Wang Qian, Hoarding of International Reserves: Mrs Machlup’s Wardrobe and the Joneses, July 2007

2066 Sheilagh Ogilvie, 'Whatever Is, Is Right'?, Economic Institutions in Pre-Industrial Europe (Tawney Lecture 2006), August 2007

2067 Floriana Cerniglia and Laura Pagani, The European Union and the Member States: Which Level of Government Should Do what? An Empirical Analysis of Europeans' Preferences, August 2007

2068 Alessandro Balestrino and Cinzia Ciardi, Social Norms, Cognitive Dissonance and the Timing of Marriage, August 2007

2069 Massimo Bordignon, Exit and Voice. Yardstick versus Fiscal Competition across Governments, August 2007

2070 Emily Blanchard and Gerald Willmann, Political Stasis or Protectionist Rut? Policy Mechanisms for Trade Reform in a Democracy, August 2007

2071 Maarten Bosker and Harry Garretsen, Trade Costs, Market Access and Economic Geography: Why the Empirical Specification of Trade Costs Matters, August 2007 
2072 Marco Runkel and Guttorm Schjelderup, The Choice of Apportionment Factors under Formula Apportionment, August 2007

2073 Jay Pil Choi, Tying in Two-Sided Markets with Multi-Homing, August 2007

2074 Marcella Nicolini, Institutions and Offshoring Decision, August 2007

2075 Rainer Niemann, The Impact of Tax Uncertainty on Irreversible Investment, August 2007

2076 Nikitas Konstantinidis, Gradualism and Uncertainty in International Union Formation, August 2007

2077 Maria Bas and Ivan Ledezma, Market Access and the Evolution of within Plant Productivity in Chile, August 2007

2078 Friedrich Breyer and Stefan Hupfeld, On the Fairness of Early Retirement Provisions, August 2007

2079 Scott Alan Carson, Black and White Labor Market Outcomes in the $19^{\text {th }}$ Century American South, August 2007

2080 Christian Bauer, Paul De Grauwe and Stefan Reitz, Exchange Rates Dynamics in a Target Zone - A Heterogeneous Expectations Approach, August 2007

2081 Ana Rute Cardoso, Miguel Portela, Carla Sá and Fernando Alexandre, Demand for Higher Education Programs: The Impact of the Bologna Process, August 2007

2082 Christian Hopp and Axel Dreher, Do Differences in Institutional and Legal Environments Explain Cross-Country Variations in IPO Underpricing?, August 2007

2083 Hans-Werner Sinn, Pareto Optimality in the Extraction of Fossil Fuels and the Greenhouse Effect: A Note, August 2007

2084 Robert Fenge, Maximilian von Ehrlich and Matthias Wrede, Fiscal Competition, Convergence and Agglomeration, August 2007 